\author{
А.А. Васильев, Н.Л. Смирнов, М.В. Соколов, И.К. Ельский, А.К. Мединцева
}

ГОО ВПО «Донецкий национальный медицинский университет имени М. Горького», Донецк

\title{
ОПЫТ РАБОТЫ СПЕЦИАЛИЗИРОВАННОГО ЦЕНТРА ПО ЛЕЧЕНИЮ БОЛЬНЫХ С ОСТРЫМ КРОВОТЕЧЕНИЕМ В ПРОСВЕТ ПИЩЕВАРИТЕЛЬНОГО КАНАЛА
}

Проблема острых кровотечений в просвет пищеварительного канала (ОКППК) остается сложной и до конца не решенной. Несмотря на достижения современной медицины, результаты лечения больных с ОКППК желают лучшего.

Высокой остается летальность при язвенной болезни желудка и двенадцатиперстной кишки, осложненной кровотечением, особенно у лиц старческого возраста и у пациентов с тяжелой сопутствующей патологией (до 40\%), а также после операций по поводу раннего рецидивного кровотечения (до 20\%). При кровотечениях вследствие синдрома лимфопортальной гипертензии летальность достигает 60\%.

Значительно увеличилось число пациентов, постоянно принимающих по медицинским показаниям антикоагулянты непрямого действия (производные кумарина) и антиагреганты. Неконтролируемый и необоснованный прием нестероидных противовоспалительных препаратов ведет к увеличению числа больных с острыми медикаментозными язвами желудка и двенадцатиперстной кишки, а также к увеличению числа больных с дивертикулярной болезнью ободочной кишки, осложненной кровотечением.

\section{ЦЕЛЬИССЛЕДОВАНИЯ}

Анализ результатов лечения больных в специализированном центре по лечению пациентов с ОКППК, изучение вопросов лечебной тактики и путей ее оптимизации у больных с ОКППК.

Для достижения поставленной цели проанализированы результаты лечения 3469 больных с ОКППК, которые находились на стационарном лечении в центре по лечению острых кровотечений в просвет пищеварительного канала г. Донецка в период с 2014 по 2018 гг.

\section{СТ РУКТУРА ОКППК}

Специализированный центр по лечению больных с ОКППК был организован в 1981 году на базе Коммунального учреждения «Централь- ная городская клиническая больница № 16 г. Донецка». Основной нозологической единицей, осложненной острым кровотечением, на протяжении 30 лет оставалась язвенная болезнь желудка и двенадцатиперстной кишки (ДПК). Традиционно, пациенты с кровотечением из острых язв и эрозий, равно, как и больные с синдромом Мэллори-Вейсса по количеству госпитализированных с ОКППК занимали второе место. В последние десять лет нозологическая структура заболеваний, осложненных ОКППК изменяется, и на первое место выходит категория больных с неязвенными кровотечениями, у которых источником геморрагии являются острые эрозивно-язвенные поражения различной локализации. Наиболее частые причины ОКППК за период 2014-2018 гг. представлены в таблице (см. табл.).

\section{ЛЕЧЕБНАЯ ТАКТ ИКА}

Главными задачами врача при ОКППК являются: оценка тяжести общего состояния пациента, своевременная диагностика источника кровотечения, достижение надежного локального гемостаза, одновременная коррекция гиповолемических нарушений, лечение основного и сопутствующих заболеваний. Указанный комплекс мероприятий предусматривает изначально мультидисциплинарный подход с участием следующих специалистов: хирурга, врачаэндоскописта, анестезиолога, врачей смежных врачебных специальностей.

Лечебная тактика при язвенных ОКППК

Лечебная тактика у больных с язвенной болезнью желудка и двенадцатиперстной кишки основывается на достижении эндоскопического гемостаза и оценке степени риска рецидива кровотечения. Наиболее эффективным считается трехкомпонентный эндоскопический гемо-

(c) А.А. Васильев, Н.Л. Смирнов, М.В. Соколов, И.К. Ельский, А.К. Мединцева, 2020 (c) Университетская Клиника, 2020 
Структура ОКППК в 2014-2018 гг.

Таблица.

\begin{tabular}{lcc}
\hline \multicolumn{1}{c}{ Причина ОКППК } & Абс. & \% \\
\hline \hline Язвенная болезнь желудка и ДПК & 1447 & 41,7 \\
\hline Острые эрозивно-язвенные поражения & 602 & 17,4 \\
\hline Синдром лимфопортальной гипертензии & 486 & 14 \\
\hline Синдром Мэллори-Вейсса & 380 & 11 \\
\hline Дивертикулярная болезнь ободочной кишки & 155 & 4,5 \\
\hline Опухоли ободочной кишки & 125 & 3,6 \\
\hline Прочие & 157 & 4,5 \\
\hline Злокачественные опухоли и полипы желудка & 117 & 3,4 \\
\hline Всего больных с ОКППК & 3469 & 100 \\
\hline
\end{tabular}

стаз, предусматривающий сочетание трех методов воздействия на источник кровотечения один из видов коагуляции, инъекционный гемостаз и нанесение пленкообразующих препаратов на источник кровотечения.

ОКППК при язвенной болезни трактуется, как пик обострения заболевания, в связи с чем с момента госпитализации больных в ОАИТ в комплексе медикаментозного лечения обязательно проводится перманентная антисекреторная терапия. Эндоскопические мероприятия по профилактике рецидива кровотечения, согласно оценке степени риска возможного рецидива кровотечения из язвы желудка или ДПК, выполняются каждые 4-8 или 12 часов. Это означает, что задача эндоскописта и анестезиолога состоит в трансформации состояния источника кровотечения от Forrest I-II к Forrest III, не допустив рецидива кровотечения.

Если до 2014 года препаратом выбора для проведения антисекреторной терапии был ингибитор протоновой помпы (ИПП), который вводили внутривенно, то с 2014 года мы отказались от применения ИПП и преимущественно используем блокаторы Н2-гистаминовых рецепторов, а в ряде случаев - селективные М-холинолитики или сочетание препаратов разных групп. При этом частота рецидива кровотечения из язв желудка и ДПК не изменилась и составляет 5,9\%. Современные препараты из группы системных гемостатических, относящихся к факторам свертывания крови, такие, как Октаплекс ${ }^{\circledR}$ (Осtaplex) и НовоСэвен ${ }^{\circledR}$ (NovoSeven $\left.{ }^{\circledR}\right)$ нами в период военного времени не использовались.

С язвенной болезнью желудка и ДПК получали лечение 1447 больных. Возраст больных от 15 до 92 лет. Консервативная терапия проводилась 1353 пациентам. Оперированы 94 (6,5\%) паци- ента. После операций смертельные случаи зафиксированы у 5 больных. Послеоперационная летальность составила 5,3\%. Общая летальность - 6,9\%. Причинами смерти после операций явились: несостоятельность швов дуоденопластики - 2, тяжелый инфицированный некротический панкреатит - 1 , острый инфаркт миокарда -1, ТЭЛА - 1. Все умершие оперированы на высоте рецидивного кровотечения.

\section{Лечебная тактика при неязвенных ОКППК}

С неязвенными кровотечениями на стационарном лечении находилось 2022 пациента. Возраст больных варьировал от 17 до 93 лет. Среди них больные циррозом печени и синдромом лимфопортальной гипертензии - 486. Один пациент оперирован, выписан с улучшением. Умерло 212 больных. Общая летальность среди больных с лимфопортальной гипертензией составила 43\%. Все умершие имели декомпенсированный класс функционального состояния печени (класс C по Child-Pugh). 128 (64\%) умерших пациентов уже имели в анамнезе кровотечения из варикозных вен пищевода и желудка. Среди умерших 52 (24,5\%) пациента были инфицированы ВИЧ, гепатитом В и С. На высоте рецидивного кровотечения скончались 40 больных, во всех других случаях смерть последовала от прогрессирующей полиорганной недостаточности с преобладаем печеночно-почечной после остановки кровотечения спустя 3-5 суток от госпитализации. К основным мероприятиям по остановке кровотечения из варикозных вен пищевода и желудка относили: эндоскопический гемостаз, постановка зонда Блэкмора, антисекреторная терапия.

Количество больных циррозом печени с синдромом лимфортальной гипертензии и кровотечением из варикозных вен желудка и пище- 
вода имеет неуклонную тенденцию к возрастанию (38 умерших больных в 2014 году и 47 умерших в 2018 году), причем возрастает удельный вес пациентов, инфицированных гепатитами В и С. Подавляющее большинство из них антиретровирусную терапию до возникновения кровотечения не получали.

С острыми язвами и эрозиями, осложненными кровотечением, за 2014-2018 гг. в клинике находилось на лечении 602 пациента. Лечебная тактика основана на ранней (в первый час при обращении, если источник кровотечения подозревается в верхнем отделе пищеварительного канала) эндоскопической верификации источника кровотечения, эндоскопическом гемостазе, полном клиническом и лабораторном обследовании пациента с выявлением причины образования острых язв и эрозий, терапии фоновых заболеваний. Наиболее частыми агентами в возникновении острых язв и эрозий явился неконтролируемый прием пациентом лекарственных препаратов. Основную группу агрессивных препаратов составили нестероидные противовоспалительные, салицилаты и, в меньшей степени, кортикостероиды.

В последние 10 лет появилась и возрастает в своем удельном весе категория больных, постоянно принимающих препараты непрямого антикоагулянтного действия, что обусловлено увеличением числа больных, перенесших рентгенэндосваскулярные хирургические вмешательства с эндопротезированием, протезирующие операции на сердце и магистральных сосудах, введением непрямых антикоагулянтов в протоколы лечения больных с постоянными формами сердечных аритмий и аортальными аневризмами. Однако, рекомендуемый врачом контроль МНО, большинством пациентов не соблюдается.

Так, на лечении с кровотечением из острых язв и эрозий в нашей клинике находились пациенты со значением МНО на момент госпитализации 8,0 - 12,0. Желудочное кровотечение из множества острых язв желудка у двух таких больных сочеталось с формированием забрюшинных спонтанных гематом. В одном случае гематома локализовалась в зоне подвздошного сегмента аорто-бедренного протеза, установленного за 1 год до обращения пациента. В условиях полного отсутствия официальных препаратов, включающих факторы свертывания крови, в комплекс инфузионной терапии включали свежезамороженную плазму, криопреципитат, транексамовую кислоту, тромбоцитартные агреганты с обязательной отменой антикоагу- лянта. Ни одного летального исхода у этой категории больных не было.

С синдромом Мэллори-Вейсса на стационарном лечении находилось 313 больных. Лечебная тактика оставалась традиционной - эндоскопический гемостаз, антисекреторная терапия с базовым препаратом из группы блокаторов Н2гистаминовых рецепторов. Эндоскопический гемостаз был эффективным в 98\% случаев. Рецидивы кровотечения при множественных или при глубоких протяженных (от 3 до 4,5 см) разрывах слизистой кардии останавливали постановкой зонда Блэкмора. Оперированных больных с синдромом Мэллори-Вейсса нет.

За последние 10 лет увеличилось и имеет устойчивую тенденцию к росту число больных с дивертикулярной болезнью ободочной кишки, осложненной кровотечением [3] Средний возраст больных, госпитализированных за эти пять

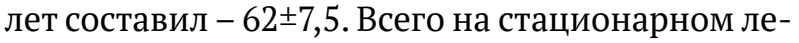
чении находилось 133 пациента. Женщины преобладают - 91\%. У 62 (47\%) пациентов дивертикулярная болезнь диагностирована впервые. Лечебная тактика так же основана на ранней верификации источника кровотечения.

При наличии клинических признаков кровотечения из нижних отделов пищеварительного тракта в любом случае диагностическую программу необходимо начинать с исключения источника кровотечения из верхних отделов пищеварительного тракта. Ректороманоскопия в первые часы от момента госпитализации, как правило, малоинформативна, часто ее не удается выполнить выше 15-18 см из-за поступления крови из вышележащих отделов кишки. Скорее она носит дифференциально-диагностический характер с целью исключения другой органической патологии прямой кишки. Такие больные, как правило, госпитализируются в ОАИТ. Методом остановки кровотечения является клизма с суспензией сульфата бария - т.н. «бариевая заглушка». Метод оказался эффективным у 121 (91\%) пациента. Рецидивы кровотечения отмечены у пациентов с хронической печеночной недостаточностью и у пациентов с хроническим приемом антикоагулянтов. Интенсивная терапия, направленная на нормализацию свертывающей системы крови и повторная «бариевая заглушка» оказались эффективными. Колоноскопия выполнялась на 6-7 сутки после остановки кровотечения. Тотальный дивертикулез ободочной кишки выявлен у 8 (6\%) пациентов, множественный дивертикулез левой половины ободочной кишки у 99 больных (74,5\%), единичные (не более 5) дивертикулы сигмовидной кишки у 26 (19,5\%). По поводу продолжающегося кро- 
вотечения из дивертикулов ободочной кишки оперированных больных нет. Анамнестически было установлено, что 117 (88\%) пациентов короткое или продолжительное время перед началом кровотечения принимали салицилаты или нестероидные противовоспалительные препараты.

Известны более 180 заболеваний, осложняющихся кровотечением в просвет пищеварительного тракта. С неязвенными источниками кровотечения оперированы 28 больных. Среди них: пациенты с кровотечением из дивертикула Меккеля - 4, с подпеченочной портальной гипертензией - 3, с опухолями желудка - 8, с опухолями ободочной кишки - 8, полипами желудка - 5. Скончались 2 пациента после операций по поводу кровоточащих опухолей ободочной кишки. Причиной летальных исходов послужила крайне тяжелая острая кровопотеря.

\section{В Ы В О д Ы}

В структуре заболеваний, осложненных кровотечением в просвет пищеварительного тракта, неязвенные кровотечения занимают лидирующую позицию.

Укоренившееся мнение об исключительной эффективности препаратов группы ингибито- ров протоновой помпы с целью проведения антисекреторной терапии при язвенной болезни желудка и двенадцатиперстной кишки, на наш взгляд, преувеличено. Использование препаратов группы блокаторов Н-2 гистаминовых рецепторов не привело к увеличению числа рецидивов кровотечения после эндоскопического гемостаза.

При отсутствии официальных препаратов, относящихся к системным гемостатическим средствам, включающих факторы свертывания крови при лечении больных с кровотечением из острых язв и эрозий, длительно принимающих непрямые антикоагулянты, эффективными остаются эндоскопический гемостаз, донорская плазма, криопреципитат, транексамовая кислота, тромбоцитарные агреганты.

С увеличением числа больных с кровотечением в просвет пищеварительного канала т.н. неязвенной этиологии, современная организация специализированного центра по лечению такой категории больных должна базироваться в многопрофильных медицинских учреждениях, оснащенных рентген-эндоваскулярной операционной. Такой подход позволит улучшить результаты лечения больных с синдромом лимфопортальной гипертензии.

\section{А.А. Васильев, Н.Л. Смирнов, М.В. Соколов, И.К. Ельский, А.К. Мединцева}

ГОО ВПО «Донецкий национальный медицинский университет имени М. Горького», Донецк.

\section{ОПЫТ РАБОТЫ СПЕЦИАЛИЗИРОВАННОГО ЦЕНТРА ПО ЛЕЧЕНИЮ БОЛЬНЫХ С ОСТРЫМ КРОВОТЕЧЕНИЕМ В ПРОСВЕТ ПИЩЕВАРИТЕЛЬНОГО КАНАЛА}

Проблема острых кровотечений в просвет пищеварительного канала (ОКППК) остается сложной и до конца не решенной. В статье рассмотрены структура ОКППК, методы и результаты лечения больных, нахо- дящихся на лечении в КУ «ЦГКБ № 16 г. Донецка» в период с 2014 по 2018 гг.

Ключевые слова: язвенные кровотечения, неязвенные кровотечения, эндоскопический гемостаз.

\section{A.A. Vasiliev, N.L. Smirnov, M.V. Sokolov, I.K. Yelskiy, A.K. Medintseva}

SEI HPE «M. Gorky Donetsk National Medical University», Donetsk

\section{THE WORK EXPERIENCE OF THE SPECIALIZED CENTER FOR TREATMENT OF PATIENTS WITH ACUTE BLEEDING IN LUMEN OF THE DIGESTIVE CHANNEL}

The problem of acute bleeding in the lumen of the digestive channel remains complex and not fully resolved. The article describes the structure of diseases, complicated by bleeding in the lumen of digestive channel, meth- ods and results of treatment patients in the period from 2014 to 2018.

Key words: ulcerative bleeding, non- ulcerative bleeding, endoscopic hemostasis. 


\section{ЛИТЕРАТУРА}

1. Кондратенко П.Г. Смирнов Н.Л. Раденко Е.Е. Острое кровотечение в просвет органов пищеварительного канала: Практическое руководство. Донецк; 2006. 420.

2. Forrest J., Finlayson N., Sherman D. Endoscopy in gastrointestinal bleeding. Lancet. 1974; 11: 395-397.

3. Strate L., Gralnek I. ACG clinical guideline: management of patients with acute lower gastrointestinal bleeding. Am J Gastroenterol. 2016; 111 (4): 459-474.

\section{REFERENCES}

1. Kondratenko P.G. Smirnov N.L. Radenko E.E. Ostroe krovotechenie $v$ prosvet organov pishhevaritel'nogo kanala: Prakticheskoe rukovodstvo. Donetsk; 2006. 420. (in Russian).

2. Forrest J., Finlayson N., Sherman D. Endoscopy in gastrointestinal bleeding. Lancet. 1974; 11: 395-397.

3. Strate L., Gralnek I. ACG clinical guideline: management of patients with acute lower gastrointestinal bleeding. Am J Gastroenterol. 2016; 111 (4): 459-474. 